\title{
Um novo nome para Deus?
}

\section{A new name for God?}

\section{Etienne Alfred Higuet*}

SIEGWALT, G. La réinvention du nom de Dieu: Où donc Dieu s'en est-il allé? Genève: Labor et Fides, 2021, 176 p.

Encontrei Gérard Siegwalt há muitos anos, na ocasião de um dos colóquios bianuais da Associação Paul Tillich de expressão francesa. Na época, ele me pediu uma resenha de um dos dez volumes da "Dogmática para a catolicidade evangélica"1, que estava em curso de publicação. O livro tratava de ecologia, na perspectiva da Teologia da Criação. Teólogo reformado, Gérard Siegwalt encerrou sua carreira de professor na Faculdade de Teologia protestante da Universidade de Estrasburgo, mas não deixou de escrever e publicar. Recebi há algumas semanas um pedido de resenha de um ensaio recente ao título instigante: $A$ reinvenção do nome de Deus. É o que me fez aceitar a tarefa.

O ponto de partida é uma constatação: Deus não pertence à realidade do tempo presente. Ninguém precisa mais dele, nem a ciência para explicar a origem e a evolução do mundo, nem os seres humanos em geral (pelo menos, no mundo europeu atual) para conduzir a sua existência. Deus tornou-se supérfluo. Trata-se, então, de completar o trabalho de luto em curso e de tentar pensar Deus de um modo novo, a partir da experiência vivida que podemos ter dele. Pois a renomeação do vazio deixado por Deus é determinante para a compreensão e assunção responsável do presente. Só poderá ser feito gritando e invocando o nome de Deus.

* Professor aposentado do Programa de pós-graduação em Ciências da religião da Universidade Metodista de São Paulo.

1 SIEGWALT, G. Dogmatique pour la catholicité évangélique. Genève: Labor et Fides, 10 vols., 1986-2007. 
O livro é dividido em três partes: aproximações, enfrentamentos, adventos, retomando a mesma questão sob ângulos diferentes. Na primeira parte, o autor mostra como a nossa civilização ocidental triunfante se esqueceu dos fundamentos permanentes, dos dados elementares do vivo e do humano. Estamos num fim matricial do nosso mundo, que incorpora as dores de parto de um mundo novo e de uma nova igreja. Do esquecimento de Deus resultou a ausência de sentido da nossa civilização dominante produtivista e consumerista, prenúncio de um novo começo em Deus e de Deus. O começo é um apelo, um grito a Deus, é a invenção ou reinvenção do nome de Deus. Trata-se de interpretar (hermenêutica), de fazer o parto (maiêutica) desse novo começo: mundo, igreja, vida pessoal e comunitária.

Para onde foi Deus? Deus se ausentou do mundo, do ser humano, e o mundo e o ser humano se ausentaram de Deus. A retração de Deus é, em primeiro lugar, uma consequência da compreensão de Deus. A mística compreende Deus como sendo além de toda representação e como sendo o próprio fundamento do real, e é a fonte da teologia negativa ou apofática. Contudo, precisamos também da teologia afirmativa, pois o ser humano, como ser de palavra, não pode se manter no silêncio perante Deus, ele precisa nomear. Isso acontece, em primeiro lugar, na teologia e, em segundo lugar, na religião. A teologia afirmativa precisa prestar contas da afirmação teológica inerente à teologia apofática, de modo crítico e autocrítico, tanto na base dos textos fundadores quanto na relação hermenêutica circular com o novo contexto histórico. Mas há compreensões teológicas que ficaram presas unilateralmente ao seu contexto, procurando tomar posse de Deus pela representação humana vinculada a esse contexto. Houve alteração do Deus vivo em Deus princípio, especialmente no supranaturalismo, no dualismo da imanência e da transcendência. Como porta-voz do transcendente, a teologia se tornou espiritualmente autossuficiente e alimentou o clericalismo colaborador do poder político pós-constantiniano. Frente ao secularismo crescente, as igrejas se tornam blocos erráticos dominados pelo comunitarismo exclusivista. Assim, a compreensão supranaturalista de Deus ficou abalada, pois Deus se retrai da sua retenção pela teologia.

A religião, do seu lado, é “a casa comunitária da fé e de sua elucidação teológica". A atual retração de Deus se manifesta pela autonomização da comunidade de fé em relação com a instituição religiosa-ministerial, especialmente das grandes igrejas históricas, e em relação com a teologia. Pode ser o germe da reinvenção da estruturação ministerial constitutiva da 
igreja, no cristianismo comunitarista, e a abertura a uma teologia não mais supranaturalista, mas centrada na experiência da fé.

Em segundo lugar, a retração de Deus está ligada ao pecado do ser humano. A noção de pecado remete a uma profundidade, não moral, mas ontológica, afirmando uma alienação do ser humano em relação à sua própria verdade, a relação com Deus. O esquecimento de Deus é o sinal dessa alienação ou ruptura. Trata-se de uma situação global, que se atesta na crise dos fundamentos da civilização moderna como julgamento imanente e como abalo do esquecimento de Deus. A modernidade, marcada pelo acesso do real imanente à sua autonomia, acabou desembocando na crise presente caracterizada pela catástrofe ecológica e climática e pela discriminação de fato entre categorias humanas: injustiças entre povos e classes sociais. Desse modo, a razão encontrou seus limites e a falência da sua pretensão autocrática. Trata-se, então, de superar a alternativa Deus - razão e de inscrever a razão na relação com Deus e Deus na relação com a razão.

A partir da crise entendida como kairós, tempo favorável, trata-se de restabelecer a relação com Deus enquanto doador, criado de todo o real e da razão como princípio de conhecimento desse real. É que o Deus esquecido continua como presença efetiva na crise de civilização e no julgamento imanente que ela constitui. Enquanto juiz, Deus constata um estado de fato; enquanto criador, redentor e salvador, Deus cria de novo a partir desse estado de fato. A partir da inadequação da compreensão supranaturalista de Deus e do esquecimento de Deus na civilização moderna, o autor deduz a necessidade de pensar Deus de um modo novo. Seria preciso abandonar a palavra Deus e a maior parte dos termos religiosos, que se tornaram incompreensíveis, e se ausentaram do espaço público? Com Bonhoeffer, o autor sugere um outro caminho: interpretar numa linguagem não religiosa as noções religiosas tradicionais. Mas seria importante também uma aculturação religiosa da sociedade, para que possa compreender as religiões presentes no seu seio como forças constitutivas, ao lado de outras, da própria sociedade. Quanto à palavra Deus, o autor a considera incontornável para expressar a profundidade de sentido na nossa vida e no mundo. O que temos que fazer é pensar Deus numa sociedade secularizada, sem Deus.

Os crentes não precisam ficar na defensiva em relação ao meio "secular". Mesmo na situação de opressão ou perseguição, eles não devem ficar na reação negativa, mas ser agentes ativos, nem que fosse no silêncio de abandono a Deus. Frente a um ateísmo difuso, raramente militante, a melhor 
atitude será o diálogo aberto, não a relação de força. Pensaremos, então, a fé e Deus além do esquecimento, que atesta uma ausência de pensamento e até uma ausência de ciência. É que não podemos deixar de aceder a um certo pressentimento do todo, ou do mistério do real, talvez a uma espera de Deus. Na civilização do esquecimento de Deus, o pensamento será um ato profético. Trata-se de, tal um peregrino, de seguir o caminho da fé ou da não fé e de perguntar aos crentes e aos não crentes: Quem é Deus e onde está ele?

Depois das "aproximações", passamos aos "enfrentamentos". Em primeiro lugar, o autor menciona a tendência humana a evitar o enfrentamento e suas causas. Essa tendência recebe o incentivo das ideologias dominantes: religiosas, como o supranaturalismo e o comunitarismo; civilizacionais, sobretudo a economia produtivista e consumerista, cujas implicações culturais são o esquecimento de Deus e a ausência de sentido da existência humana e do mundo, isto é, o niilismo. O esquecimento de Deus deriva do esquecimento da unidade do real, consequência da modernidade. É o esquecimento do real como criação, o esquecimento de Deus sendo o esquecimento do Criador.

O choque do real atual se explicita em três catástrofes: ecológica e climática; social; humana pessoal. A primeira marca o fim do mundo da modernidade e apela e anuncia, a partir da razão, uma outra civilização, consciente da sua relação unificadora com o mistério do real: origem, finalidade e transcendência. Deus é o nome balbuciado que damos a esse mistério que carrega todas as coisas. Daí nasce um caminho da razão e da sua sabedoria rumo à fé como temor e veneração de Deus. A catástrofe social consiste na catástrofe societal da justiça entre os povos e as categorias sociais, ameaça maior para a coesão e a sobrevivência dos humanos. Ela abre o abismo da barbárie. Por sua vez, a terceira catástrofe diz respeito à infelicidade, ao mal sofrido e à questão do seu sentido. Ela concerne também a realidade da culpa, do mal agido que torna culpado e de seu alcance para o ser humano culpado e para outrem. Coloca-se a questão do perdão, da libertação da alienação pessoal e da reconciliação com outrem, e ainda, em todos os sentidos, da salvação e da paz. De novo, encontramos aí um apela à razão entendida como pensamento e, logo, à fé religiosa entendida como temor a Deus. O choque do real atual é a porta de entrada para a questão: quem é Deus e onde está ele?

Mas, para deixar o grito advir ao seu sentido na palavra e para evitar a fuga num futuro sonhado, utópico, precisamos do choque da 
memória crítica do passado. As causas da barbárie presente se enraízam no passado das tradições religiosas anteriores à modernidade e que a carregam: supranaturalismo, teocracia, comunitarismo. Ao se distanciar de suas aberrações, as religiões podem redescobrir a sua essência espiritual e a experiência de base que as sustenta. As religiões possuem recursos nos seus textos fundadores e nas suas práticas de fé atuais. Elas devem também considerar a dimensão plural inter-religiosa do universo das religiões, fundamento de um diálogo reciprocamente crítico, em vista de levar a sua contribuição específica ao bem geral. A responsabilidade atual das religiões reside num choque de visibilidade, de atualidade e de credibilidade, endireitando os desvios do passado.

Nesse sentido, as religiões haverão de prestar contas de si mesmas, e do espírito dos seus textos fundadores, isto é, da palavra viva do Deus vivo, rejeitando todo fundamentalismo. Por outro lado, a compreensão da fé evolui ao longo da vida de cada pessoa, e a mensagem permanente precisa ser redescoberta de uma nova forma em cada geração. A transmissão opera através de uma tradição viva de fé, que é da ordem do carisma e do dom, e que consiste numa interpretação e atualização dos escritos fundadores. Tratase de encontrar o sentido desses textos, em função do seu contexto primeiro e do seu contexto atual. Ele pressupõe também a correlação entre a atualidade em geral e a questão de Deus que aparece nela: questão do sentido, da justiça, da salvação. A hermenêutica dos escritos fundadores é colocada a serviço da hermenêutica do grito. Só pode acontecer em diálogo reciprocamente crítico com os porta-vozes do real vivido e dos seus desafios, por meio de uma teologia responsiva, a única verdadeiramente responsável.

A atualização dos textos fundadores é o fato de um Kairós, de um tempo divino, de plenitude: o choque da profecia. O kairós comporta dois momentos: o da revelação e o da efetivação: o kairos-dom é, de fato, kairostarefa ou responsabilidade. As características da profecia são a espiritualidade e a inventividade ou criatividade: é o Espírito criador de Deus que advém a si mesmo no ser humano e na sua fé. Acontece tanto na procura por Deus quanto na transmissão, como no caso dos profetas e dos apóstolos. Hoje, só pode haver profecia na junção do grito da terra e da tradição da fé, e na conjunção da fé e da razão frente ao mistério do real.

A terceira parte, "Adventos" (Advenues), começa com a recapitulação dos freios ao advento do grito, sobretudo o recalque devido ao conformismo, e dos freios ao advento do sentido do grito, a deficiência da linguagem e 
a insuficiência de acompanhamento cultural, psicológico e espiritual, assim como a ausência de alternativa refletida e coerente. Contudo, a explosão do grito não pode ser contida por muito tempo. Ela tem duas formas: o niilismo ou absolutização do grito, que leva à destruição e à anarquia; a assunção do grito pela sua nomeação e expressão do seu sentido, e as respostas trazidas a esse sentido. É o sentido construtivo do grito.

$\mathrm{O}$ autor elenca três passos nesse advento do grito: do esquecimento ao balbucio do nome; o parto do nome; a efetividade performativa do nome. A consciência pré-moderna de Deus nas religiões já entrou no esquecimento. As religiões procuram se recontextualizar nos seus novos meios culturais, a partir de uma reconsideração crítica de seu fundamento respectivo. Mas o esquecido continua ativo e acaba inundando aos poucos a consciência humana geral. O choque do real coloca em questão o esquecimento de Deus. Trata-se de desconstruir o esquecimento de Deus que resultou da revanche moderna da razão autônoma. Estamos no kairós da construção de uma nova era.

Estamos no momento do balbucio do nome que procede do grito arquetípico do todo - bolístico e teônomo -, e que anuncia o que ainda não adveio, mas é suscetível de advir. Além do esquecimento de Deus, está chegando o apelo ao que faz viver e à pergunta: quem é Deus e onde está ele? Está chegando o apelo ao sentido, à justiça e à salvação. Chegamos assim ao segundo passo, que é o parto do nome.

O parto do nome consiste, em primeiro lugar, na quebra do interdito ou do tabu Deus, especialmente na esfera pública: a quebra do laicismo como ideologia do esquecimento de Deus. É preciso rejeitar, ao mesmo tempo, a perversão da religião à procura do poder temporal e a perversão do Estado no sentido do totalitarismo, da negação da liberdade religiosa. Isso começa pela quebra da autonomia absolutizada da razão. Tampouco podemos substituir Deus por ídolos, como o dinheiro ou o ego absolutizado. Os valores fundamentais da existência humana se atestam nos desafios políticos que são a preservação da terra e a justiça entre os povos e os seres humanos. As religiões testemunham da fonte transcendente ou divina desses valores, o que lhes dá uma radicalidade propriamente religiosa no sentido de holística e transcendente/teônoma. Esses valores serão submetidos à provação nos percalços pessoais e coletivas da história. O que inclui a interpelação recíproca do espiritual e do temporal. Há que superar a tentação do imperialismo das religiões em relação ao temporal, no que seria uma espécie de revanche teocrática ou fundamentalista. As 
religiões precisarão também acompanhar o balbucio do nome de Deus, a sua reinvenção, que está se desenhando.

Em segundo lugar, o parto é o combate espiritual da consciência dos desafios radicais, em vista da clarificação do que é verdadeiramente o maior bem e da mobilização de todos os recursos disponíveis para a realização desse bem. Necessita, na esfera religiosa, de humildade, discernimento e coragem.

O terceiro passo é o mais importante: o parto, através do balbucio, como nomeação do nome. O nome de Deus a reinventar aparecerá na compreensão transcendente dos valores temporais já mencionados, na percepção do significante de transcendência carregado pelo mistério do real. Aliás, a revelação sempre operou dessa maneira, como nas parábolas de Jesus e os sinais de Alá como criador no alcorão. Deus é um tesouro escondido nas profundezas do real. Isso se manifesta nos nomes bíblicos de Deus e nos 99 nomes de Alá. É que o espiritual é a dimensão de profundidade do temporal, cuja iluminação no passado foi recolhida pelas religiões e expressa nos nomes ou atributos de Deus como nos inúmeros "rostos" dele. A iluminação é a irrupção na consciência humana de alguém que faz brilhar o significante do real pelo fogo de luz do seu sentido. Aqui é fundamental o papel das testemunhas que são os profetas, os apóstolos e os fundadores de religiões.

A iluminação se manifesta nas narrativas e nos ritos fundadores, e precisa percorrer um longo caminho de clarificação, aprofundamento e alargamento. O resultado da aliança do baixo (temporal) e do alto (espiritual, transcendente) é o nome reinventado de Deus, como nome dado, logo, recebido. Nome novo reinventado em diálogo crítico com o nome velho recebido do passado. Nome reinventado de Deus que suscita a reinvenção do nome do ser humano, que lhe confere um rosto pessoal. O desafio final é o novo nome profético de DEUS.

O terceiro advento é a efetividade performativa do nome. É na fé que o nome de Deus se prova, na aposta da confiança no nome de Deus e nos nomes que o explicitam. Frente ao real, o nome de Deus mostra o seu poder, a sua capacidade real, efetiva de unificar holisticamente o real: o cosmos e a terra, a humanidade e os povos, a pessoa humana individual e comunitária, no respeito da sua diversidade diferenciada e irredutível. A nomeação justa é construtiva, nunca acabada, pois Deus está além de todo nome, no diálogo entre a fé e a razão. A apropriação do nome consiste em dizer sempre novamente o nome reinventado, mas também fazer silêncio ao nomear, pois o nome, os nomes sempre remetem além deles mesmos. Trata-se de se pôr a caminho. 
O livro de Gérard Siegwalt vale, sobretudo, pela sua clareza e o seu didatismo, ao usar um método próximo do "ver, julgar, agir", podendo assim alcançar um amplo público não especialista. Está repleto de boas intuições, como a ausência de Deus na realidade atual, a necessidade de uma hermenêutica permanente da situação atual, a percepção do perigo do comunitarismo fundamentalista, a superação da compreensão do pecado como culpa, a necessidade de uma linguagem não religiosa, a relação íntima da fé e do pensamento, a necessidade de relativizar o laicismo. Ele traz título e subtítulos evocadores e metáforas sugestivas, como grito, balbucio, parto, choque profético. O projeto bem acertado de reinventar o nome de Deus está na linha das propostas atuais de um "paradigma pós-religional" (Mariah Corbi) ou de um "anateísmo" (Richard Kearney). ${ }^{2}$ Podemos mencionar também a crítica do supranaturalismo e do teísmo por Paul Tillich. Ele compartilha ainda a sua intuição de base com os filósofos adeptos da desconstrução, como Derrida e Nancy, que resgatam a tradição bíblica da nomeação.

$\mathrm{Na}$ sua preocupação em não perder o contato com a teologia clássica, ele poder ter ficado um pouco abstrato e tímido nas suas sugestões. Ele mesmo poderia arriscar algum nome novo para Deus, sem se contentar em dar uma nova vida aos antigos nomes, especialmente bíblicos. Ele poderia ousar mais, criticar os teísmos, mergulhar mais no concreto. Ele poderia encontrar "escritos fundadores" em toda a história das tradições religiosas, inclusive nos chamados "apócrifos", nas chamadas "heresias", como o gnosticismo, resgatado pela teologia feminista, e no cristianismo oriental, lutando contra a extinção no Iraque, na Síria, no Irão. Há também a história da recepção - sincrética - das tradições religiosas, e todos os debates intra- e inter-religiosos, todos os conflitos de interpretação de milênios de história religiosa. Enfim, filósofos e artistas estão também à escuta do "grito" e há um niilismo positivo, por exemplo, em Vattimo.

Por último, a reflexão poderia atravessar as fronteiras do Velho Mundo. Assim, no Brasil e na América latina, há necessidade de um processo de "descolonialização" dos nomes, de reinvenção do nome de Deus na diversidade cultural, de gênero etc. Precisamos superar a "demonização" dos vencidos, as inquisições de todo tipo, como a perseguição dos "cristãos novos", o sufoco

2 Ver, por exemplo: KEARNEY, R. Anatheism. New York: Columbia University Press, 2011; ID. The God who may be: A Hermeneutics of Religion. Bloomington: The Indiana University Press, 2001; VIGIL, J. M. (Org.). Paradigma pós-religional. Número especial de Horizonte, Vol. 13, n. 37, jan/mar. 2015. 
da "bruxaria", o massacre das religiões ameríndias e africanas. Não parece que o tabu Deus exista aqui, ao contrário, o nome de Deus continua sendo manipulado e domesticado, inclusive pelas mais altas autoridades.

Tenho consciência de estar pedindo demais, levando em conta os limites de um ensaio, e peço desculpas por isso ao autor. Deixo as sugestões para um próximo trabalho. Estamos realmente no kairós de uma nova era? Só o futuro o dirá. Por enquanto, só nos resta cultivar a esperança. 